ORIGINAL ARTICLE

\title{
Optimizing injectable poly-L-lactic acid administration for soft tissue augmentation: The rationale for three treatment sessions
}

\author{
Ute Bauer MD ${ }^{1}$, Miles H Graivier MD²
}

U Bauer, MH Graivier. Optimizing injectable poly-L-lactic acid administration for soft tissue augmentation: The rationale for three treatment sessions. Can J Plast Surg 2011;19(3):e22-e27.

BACKGROUND: The availability and variety of different injectable modalities has led to a dramatic increase in soft tissue augmentation procedures in recent years. Injectable poly-L-lactic acid (PLLA) is a synthetic, biodegradable polymer device approved in the United States for use in immunocompetent patients as a single regimen of up to four treatment sessions for correction of shallow to deep nasolabial fold contour deficiencies and other facial wrinkles. Injectable PLLA is also approved for restoration and/or correction of signs of facial fat loss (lipoatrophy) in individuals with HIV.

METHODS: The present article provides an overview of previous studies with injectable PLLA, and specifically focuses on the number of recommended treatment sessions and intervals between treatment sessions. The authors also provide two case studies to support their recommendations for an average of three treatment sessions.

RESULTS: Although the specific mechanisms remain hypothetical, injections of PLLA are believed to cause a cascade of cellular events that lead to collagen repair and subsequent restoration of facial volume. Because the development of a response to injectable PLLA is gradual and its duration of effect is long lasting, sufficient time between treatment sessions should be allocated to avoid overcorrection.

CONCLUSION: Studies of injectable PLLA support the hypothesized mode of operation, and the experience and clinical recommendations of the authors that suggest that three treatment sessions are an optimal regimen for use of injectable PLLA in the majority of patients.

Key Words: Collagen; Cosmetic; Dermal fillers; Injectable devices; Injectable PLLA

$\mathrm{T}$ he availability and variety of nonsurgical soft tissue augmentation options led to a $90 \%$ proportionate increase in minimally invasive cosmetic procedures from 2000 to 2008 (1). Age-related alterations to the face result from normal physiological processes (ie, facial skeletal resorption), dermal dystrophy, dermal thickening owing to photoaging or thinning resulting from chronological aging, loss (facial lipoatrophy) or redistribution of facial fat, and the appearance of facial wrinkles $(2,3)$. Facial volume loss can also occur in patients receiving antiretroviral therapy for HIV, and can be the result of other diseases involving inherited or acquired lipodystrophies such as familial partial lipodystrophy (Dunnigan or Köbberling variety), Parry-Romberg syndrome and Barraquer-Simons syndrome (4-6).

A wide range of injectable devices for soft tissue augmentation is available in Europe and the United States (7) including hyaluronic acids, calcium hydroxylapatite, polymethylmethacrylate microspheres, injectable poly-L-lactic acid (PLLA) and silicone oil (8). Hyaluronic acid and collagen preparations are safe and effective; however, the results only typically last between three and 12 months (7,9-13). The use of bovine-derived collagen requires allergy testing and is generally effective for approximately three months. Human-derived collagen does not require allergy testing (14), and the effects can last up to four

\section{L'optimisation de l'administration d'acide} L-polylactique injectable pour augmenter les tissus mous : la justification de trois séances de traitement

HISTORIQUE : La disponibilité et la variété de différentes modalités injectables a donné lieu, ces dernières années, à une augmentation considérable des interventions d'augmentation des tissus mous. L'acide L-polylactique (PLLA) injectable est un polymère biodégradable synthétique approuvé aux États-Unis auprès des patients immunocompétents, sous forme de schéma posologique unique d'un maximum de quatre séances de traitement pour corriger les anomalies du contour des sillons nasolabiaux légers à profonds et d'autres rides faciales. Le PLLA est également approuvé pour restaurer ou corriger les signes de perte lipidique (lipoatrophie) faciale chez les personnes atteintes du VIH. MÉTHODOLOGIE : Le présent article propose un aperçu d'études antérieures sur le PLLA injectable et s'attarde sur le nombre de séances de traitement recommandées et sur les intervalles entre ces séances. Les auteurs présentent également deux études de cas pour étayer leur recommandation de prévoir une moyenne de trois séances de traitement. RÉSULTATS : Même si les mécanismes précis demeurent hypothétiques, on pense que les injections de PLLA provoquent une cascade d'événements cellulaires qui suscitent la réparation du collagène et une restauration subséquente du volume facial. Puisque la réponse au PLLA injectable est graduelle et que son effet est de longue durée, il faut prévoir une période suffisante entre les séances de traitement afin d'éviter une surcorrection. CONCLUSION : Les études sur le PLLA injectable appuient le mode d'utilisation postulé ainsi que l'expérience et les recommandations cliniques des auteurs selon lesquelles trois séances de traitement constituent la posologie optimale d'utilisation du PLLA chez la majorité des patients.

to seven months (15). Newer silicone oils have been shown to be effective for facial lipoatrophy; however, no long-term follow-up studies of adverse effects have been reported, particularly with regard to the incidence of severe foreign body reactions - a complication that was associated with the older formulations (16). Calcium hydroxylapatite has a suggested duration of approximately 12 months and a favourable safety profile (17). Injectable PLLA has demonstrated effectiveness for the correction of shallow to deep nasolabial fold contour deficiencies and other facial wrinkles (18), and in restoring facial fat loss due to HIVassociated lipoatrophy; its effects last up to 25 months (19-22).

The purpose of the present article was to offer a rationale for the use of three treatment sessions, on average, of injectable PLLA (Sculptra Aesthetic, Dermik Laboratories, sanofi-aventis, USA) to obtain long-lasting and gradual correction of facial folds and wrinkles such as nasolabial folds in immunocompetent patients (ie, those without HIV-associated facial lipoatrophy). Two case studies are presented to illustrate this approach. The recent approval of injectable PLLA in the United States for use in immunocompetent individuals as a single regimen of up to four sessions for the correction of shallow to deep nasolabial fold contour deficiencies and other facial wrinkles provides further support for the three-treatment approach (18). Injectable

${ }^{1}$ Clinica Diaz, Padova, Italy; ${ }^{2}$ North Atlanta Plastic Surgery, Roswell, Georgia, United States

Correspondence: Dr Ute Bauer, Chirurgia Plastica ed Estetica, Casa Di Cura Diaz, Via Diaz 9, 35100 Padova, Italy. Telephone 39-348-243-5380,

fax39-049-871-1342, e-mail ute.bauer@tin.it 
PLLA is also approved for the restoration and/or correction of the signs of facial fat loss (lipoatrophy) in people with HIV (19). Injectable PLLA is a synthetic, biocompatible, biodegradable, polymeric device. Because its effects develop gradually and are sustained for up to 25 months $(18,19)$, clinicians need to understand the dynamics of the product to ensure its optimal use in soft tissue augmentation and minimize the occurrence of adverse events.

\section{INJECTABLE PLLA:} THE RATIONALE FOR THREE INJECTION SESSIONS Studies in animals have shown that the implantation of solid PLLA particles, plates, discs, pins or screws produces a cascade of events that results in the formation of new tissue (23-28). In humans, Lemperle et al (25) observed a cellular response (involving macrophages, lymphocytes and giant cells), which was similar to that seen in mice after reconstituted PLLA (New-Fill, Biotech Industry SA, Luxembourg) was injected into the volar skin of the forearm. Treatment with injectable PLLA has also been reported to result in the gradual growth of type I collagen for eight to 24 months (2). Although additional studies in humans are necessary to more accurately determine the mode of operation of injectable PLLA, the studies described above provide a logical framework to guide the use of the device for the correction and/ or restoration of nasolabial fold wrinkles.

Based on the hypothesized mode of operation discussed above, injections of PLLA into the deep dermis or subcutaneous layer are believed to induce a local tissue reaction that may lead to the redevelopment of the collagenous network lost due to aging or disease and, ultimately, the restoration of collagenous scaffolding within the tissue $(29,30)$. Because this cellular cascade occurs over time, injectable PLLA has a gradual treatment effect, and the application of additional treatments before the results of the previous treatment are apparent can result in overtreatment of the area. The time to response and ensuing signs of correction depend on the individual, owing to interpersonal differences in age, skin type and skin quality; moreover, results may not be evident for up to several weeks after treatment - an effect that is unlike that of collagens and hyaluronic acids $(29,31)$. Therefore, it is important to wait for the underlying biological response (ie, cellular cascade) to occur between each treatment; a limited correction should be made with the first treatment session (19). It is also crucial to assess the effects of each previous series of injections to determine what refinements are needed before proceeding with additional treatment. This has been previously described in the literature as the 'treat-wait-assess' approach, and has been successfully applied in the correction of HIV-related facial lipoatrophy and for volume restoration in antiaging treatment $(32,33)$.

Each treatment with injectable PLLA potentially elicits the cellular cascade of events that is believed to lead to collagen formation, in which the magnitude of response is dependent on the volume of injectable PLLA used. Because of variations in the severity of the nasolabial fold volume deficits among patients, the volume of injectable PLLA used for each patient will differ. However, this volume should never be in excess of the initial loss in facial volume or the severity of the facial wrinkle, nasolabial line or fold, which is overcorrection, and is not recommended. The first treatment with injectable PLLA elicits an observable response because of mechanical tissue expansion from the injected volume (reconstituted with sterile water for injection), facilitating a noticeable correction of contour deficiencies $(29,31)$. This initial effect will likely subside owing to partial resorption of the carrier solution, although the first stages of the underlying dermal structural restoration are believed to begin here $(2,31)$. Consequently, it is common for the initially observed correction of the contour deficit to return to pretreatment status a few days after the first injection; thickening of the soft tissue usually increases again after the first several weeks $(19,31)$. Subsequent injections, in theory, provide continued stimulation of the tissue response, resulting in further refinement of volume replacement for long-term improvement of facial contour deficits (34). Thus, based on the hypothesized foreign body response to the injected microparticles of PLLA (or other injected fluids or particles) $(35,36)$, each treatment is believed to result in the formation of collagen that replaces lost volume (21). The extent of volume restoration and collagen formation, however, may be dependent on the volume of injectable PLLA used in each treatment and on interindividual differences.

Because the proposed mode of operation of injectable PLLA involves a tissue response, sufficient time needs to be allowed for that response to occur. Consequently, based on our experience, we recommend that patients be re-evaluated at an interval of no less than three weeks before the second treatment and three months before the third treatment. These intervals will allow sufficient time for the underlying tissue processes involved in the correction to take place and become observable following treatment with injectable PLLA. In our experience, patients with greater overall skin thickness may require a longer period between treatment sessions (up to several months) before the full effect of treatment becomes apparent $(20,37,38)$.

The use of three treatment sessions of injectable PLLA is supported by earlier studies evaluating the efficacy and safety of injectable PLLA in patients with HIV-associated facial lipoatrophy. The VEGA study (20) used an average of four treatment sessions, the Chelsea and Westminster trial $(21,22)$ involved three treatment sessions and the Blue Pacific Group study (39) used up to six treatment sessions with injectable PLLA at three- to six-week intervals. Although HIVassociated facial lipoatrophy may be mechanistically distinct from the volume loss and contour deficiencies encountered in the typical patient with age-related volumetric loss, the above studies support the need for more than two injection sessions to achieve optimal, fully visible effects with injectable PLLA. The recent approval of injectable PLLA in the United States for use in immunocompetent individuals (18) allows its use for aesthetic purposes in a wider range of patients. This approval was based on a single study of injectable PLLA (40), which is discussed later in the present article.

\section{OPTIMIZING INJECTABLE PLLA RESULTS FOR SOFT TISSUE AUGMENTATION}

Based on the hypothesized mode of operation of injectable PLLA, and supported by the authors' clinical experience, three treatment sessions are recommended to gradually restore facial volume in the typical cosmetic patient. The authors' experience with injectable PLLA began in 1999 and, since that time, approximately 4000 patients have been treated with this injectable device. Most patients favour gradual aesthetic change so that their friends and family remain unaware of their soft tissue augmentation treatments (41). For a new patient, at least four weeks should separate the first two treatments, and the patient should wait least three weeks before the third treatment. Moreover, the authors' clinical experience with injectable PLLA has indicated that six months should elapse after the third treatment before any further assessments. The observations suggest that this time interval is sufficient to determine the extent of the correction achieved by the first three treatment sessions and to assess the need for additional treatments. At the same time, this approach minimizes the risk of overcorrection of the injected area and reduces the risk of adverse events including development of papules and nodules. Finally, the total injection volume will vary, depending on the area of the deficit requiring correction, the patient's age and skin quality. The treatment area should be massaged periodically during and following each injection to ensure even distribution of the product (19). Most importantly, patients should be instructed to massage the treatment area following the 'three five rule' - massage the area for $5 \mathrm{~min}$, five times a day, for at least five days $(34,42,43)$. Using the injection technique described in the package insert is also recommended for minimizing the occurrence of adverse events.

\section{CASE STUDIES}

According to the package insert, injectable PLLA should stand for at least $2 \mathrm{~h}$ after reconstitution to ensure complete hydration. However, in 


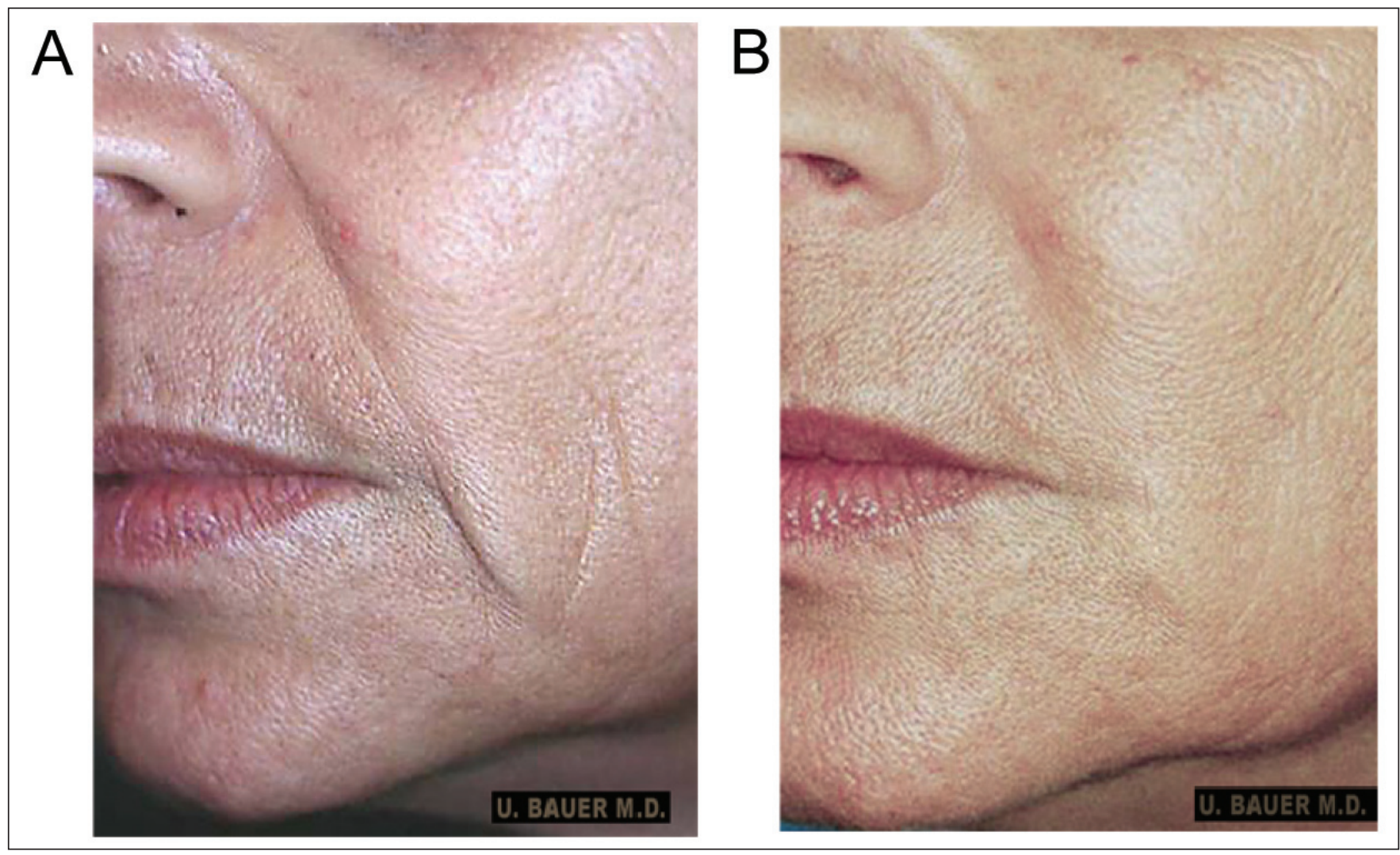

Figure 1) Patient 1: A 55-year-old Caucasian woman, before (A) and 12 months after (B) the third injectable poly-L-lactic acid treatment. Notice the degree of correction in the nasolabial fold region and in the marionette line

the authors' experience, a better suspension is achieved when reconstitution is performed at least $12 \mathrm{~h}$ before use (44). Five millilitres of sterile water for injection should be added to each vial, although many clinicians, including the authors, reconstitute PLLA with $4 \mathrm{~mL}$ of bacteriostatic water for injection and add $1 \mathrm{~mL}$ to $3 \mathrm{~mL}$ of lidocaine to minimize injection pain (45). The reconstitution volume, however, is not the same as the injection volume; approximately 20 aliquots of $0.1 \mathrm{~mL}$ to $0.2 \mathrm{~mL}$ ( $2.0 \mathrm{~mL}$ to $4.0 \mathrm{~mL}$ total injected volume) of reconstituted injectable PLLA may be necessary to cover the targeted area (19). It is recommended that injectable PLLA be administered using 26-gauge needles and be injected into the deep subdermis or subcutaneous layer. Firm massage is used to evenly distribute injectable PLLA. In older patients, maxillary bone and soft tissue changes may result in elongation of upper lip length and change in the proportion of the lower one-third of the face (46). In these patients, injection into the supraperiosteal plane helps to elevate the soft tissue and can positively modify the lower facial proportion (46), although this use of injectable PLLA has not been approved by the United States Food and Drug Administration. Additionally, in patients with deep nasolabial folds (wrinkle rating severity scale of 3, 4 or 5) (47), supraperiosteal injection at the pyriform aperture will give improved correction (46). After reconstitution, vials of injectable PLLA can be stored at room temperature for up to $72 \mathrm{~h}$ before use $(18,19)$.

Patient 1 was a 55 -year-old Caucasian woman who was a smoker. She had thin skin, which remained void and pinched when tested before treatment. The poor quality of her skin was typical of smokers who generally have reduced microcirculation in their skin; furthermore, less nutrition is provided to the outer dermal layer, thus drying the skin layers, creating fine wrinkling and promoting faster aging. In addition, the nicotine deposited in the patient's skin diminished its colour, giving the skin a grayish pallor $(48,49)$.

Lossof facial fat and resultant hollowing contributed to the patient's tired and older appearance. In the authors' experience, extreme care with injections into very thin skin layers is needed because even a minor error, such as an uneven distribution of injectable material, may cause irregular results. In these instances, lower injection volumes (ie, one injection of less than $0.1 \mathrm{~mL}$ ) of more dilute injectable PLLA are used, with a reconstitution volume of up to $6 \mathrm{~mL}$ to $7 \mathrm{~mL}$. The authors also insist that the patient performed regular aftercare massage of the injected area. Based on the hypothesized mode of operation, injectable PLLA provides structural support by inducing a tissue response leading to collagen development, thus creating a suspended net under the entire area of the deficit or fold. Therefore, with older patients, such as the present 55-year-old woman, injectable PLLA should be injected just above the area of the nasolabial fold and extended widely outside the defect to create a lifting effect. In addition, PLLA should be injected into the deep dermal layer or subcutaneous layer (19), but never into the dermis. In fact, some physicians, including the authors, elect to inject the device into the supraperiosteal layer, although this method is considered to be off label (46).

After the initial consultation, the patient was interested in a gradual, long-lasting, minimally invasive corrective procedure, and requested treatment with injectable PLLA to soften and fill out her nasolabial folds (Figure 1A). The use of hyaluronic acid-based products was also discussed, but was discounted because of their shorter duration of effect compared with injectable PLLA, and the need for a large amount of filler material to correct the patient's deficit. The reconstituted product was injected bilaterally into the area slightly above the nasolabial folds. The patient received three treatments over 12 weeks. Because of her poor skin quality, four weeks were allowed between her first and second treatment, thus giving sufficient time for the collagen restoration and repair processes to begin. Four weeks after her first treatment, the patient was assessed as having little or no observable cosmetic improvement. This result was not unexpected because the initial observable improvement was largely due to mechanical expansion of the carrier and mostly subsided to pretreatment 

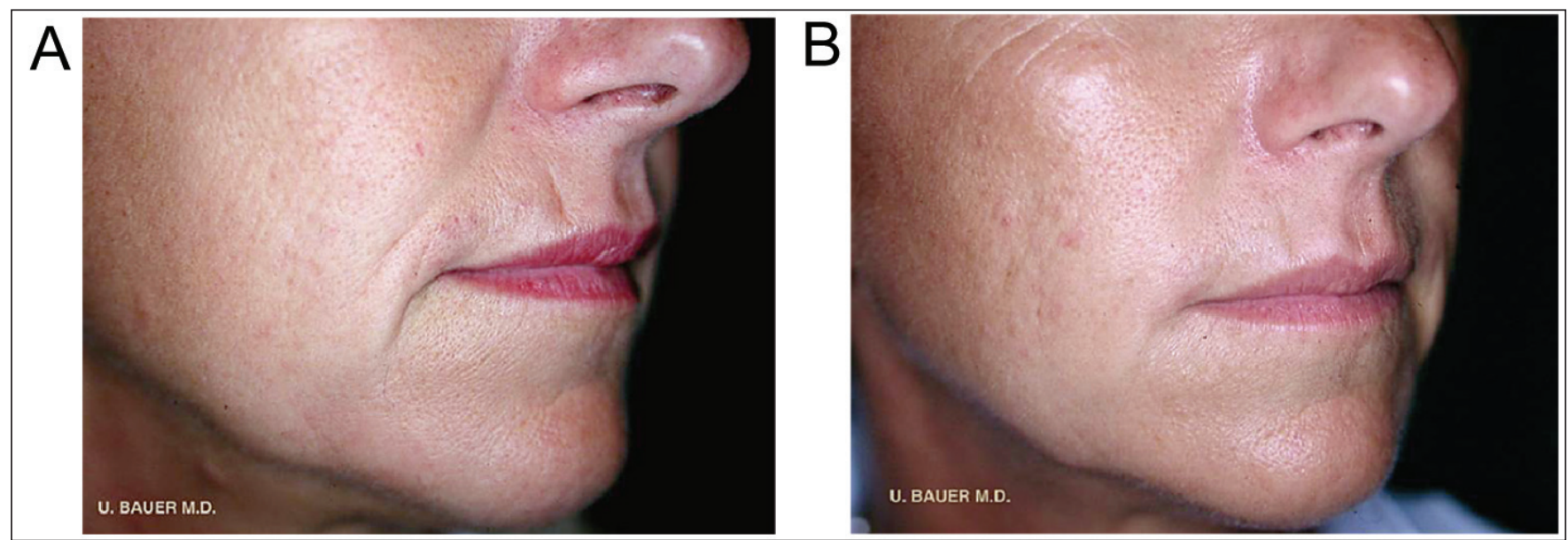

Figure 2) Patient 2: A 45-year-old Caucasian woman, before (A) and 24 months after (B) the third injectable poly-L-lactic acid treatment. Hyaluronic acid in superficial lines. Reproduced from reference 56

levels in approximately one week (29,31). After the second treatment, a $20 \%$ to $30 \%$ improvement in tissue quality and growth was noted, based on the authors' clinical experience, comparison of the patient's photographs before and after treatment and the patient's opinion regarding the treatment results. A third treatment was administered eight weeks after the second treatment to continue the restorative collagenous repair and refine the improvement in the nasolabial region. Each treatment was well tolerated, with no adverse events reported.

After completing her treatment, the patient presented with good correction of the nasolabial fold and marionette lines, and improvement in her skin quality, with an enormous gain in elasticity; this was based on visual inspection by the physician and patient as well as through comparison with pretreatment photographs. Figure $1 \mathrm{~B}$ shows the area of injection 12 months after the third and final treatment with injectable PLLA. For this patient, improved skin quality led to an increase in the fibrotic layer in the dermis and subdermal layer, which could be manually ascertained in the skin layer overlying the site treated with injectable PLLA. A thicker skin layer also reflects light better as the deep shades disappear because of the improved convexity of the facial contours (50). With restoration and repair of the underlying collagen in the nasolabial fold region, the patient's face and skin appeared healthier, her pores were reduced and the overall roundness (convexity) in the middle of her face gave her a more youthful appearance. The patient has returned for yearly follow-up assessments. In the five years since her initial treatment with injectable PLLA, the patient has maintained the underlying correction without any adverse events. She has also reported very high satisfaction with her treatment. Since her treatment with injectable PLLA, the patient has returned for two additional Fraxel laser treatments (Thermage, Solta Medical Inc, USA). She also received two treatments with hyaluronic acid to address her more superficial wrinkles.

Patient 2 was a 45-year-old, healthy, nonsmoking, active Caucasian woman. The patient's objective for treatment was to lose the 'negative expression' on her face (Figure 2A). She had previously tried hyaluronic acid-based fillers and now desired a longer lasting and more overall correction. Based on discussions with the patient concerning the degree of correction she desired, it was agreed that treatment with injectable PLLA would provide her with the correction she sought. Because lost or damaged collagen likely contributed to her 'negative expression' (51), there was a four-week interval between her first and second treatments with injectable PLLA to allow for the effects of the treatment to take place. After assessing the improvements of the second treatment, the authors waited eight weeks before administering the third treatment. In each treatment session, injectable PLLA was reconstituted to a final dilution of $5 \mathrm{~mL}$ ( $4 \mathrm{~mL}$ of sterile water for injection plus $1 \mathrm{~mL}$ of lidocaine) and was allowed to stand for up to $48 \mathrm{~h}$ before use, as previously discussed. Bilateral injections of $2 \mathrm{~mL}$ of injectable PLLA were made above the nasolabial fold region. Each treatment was well tolerated. For this patient, the areas of improvement included the nasolabial fold region, marionette lines and the area above the lip (Figure 2B). After three treatments, the convexity of her nasolabial fold region had been restored, virtually eliminating the fold and marionette line. She maintained very good improvement in the nasolabial fold region for 24 months following the final treatment (Figure 2B). She remains very satisfied with her treatment and has not reported any adverse events. The patient was assessed 36 months after her final treatment session and has returned annually for the past four to five years for follow-up. She continues to show very good correction and has required additional treatment with injectable PLLA only in the zygomatic area. She, however, continues to receive treatment with one vial of hyaluronic acid yearly for superficial wrinkles.

\section{DISCUSSION}

Interest in delaying the visible signs of aging, such as progressive volume loss, thinning of the dermis and a loss of continuity caused by lines, wrinkles and deep furrows, combined with the greater availability and variety of noninvasive injectable fillers, likely account for the increased interest in soft tissue augmentation procedures (52). Injectable PLLA has been shown to be safe and effective in the management of facial lipoatrophy, in patients with and without HIV who are seeking soft tissue augmentation. The cases presented in the present article show that injectable PLLA is an appropriate nonsurgical option for soft tissue augmentation.

Our clinical experience with injectable PLLA suggests that three treatment sessions provide an optimal regimen for most immuncompetent patients. This practice is based on the treat-to-repair, wait-torestore and assess-to-refine concept $(32,33)$, wherein each series of injections is believed to contribute to a foreign body response. Because each patient responds differently to treatment with injectable PLLA, it is important to allow sufficient time between treatments to avoid overcorrection of the original deficit. Overcorrection of the injected area may produce an unwanted visual effect, and may contribute to the formation of subcutaneous nodules $(31,53,54)$. It should be emphasized that the effects of treatment with injectable PLLA are gradual and long lasting (55). A minimum of three- to four-week intervals between treatment sessions allows for the effect of injectable PLLA, namely the cellular cascade responsible for collagen repair and restoration, to occur. Providing the time for the cellular processes for collagen repair and restoration to occur also minimizes the risk of overcorrection.

Our treatment approach is supported by earlier studies (20-22,39), in which patients with HIV-associated facial lipoatrophy were successfully treated with injectable PLLA using an average of three treatment sessions. Although HIV-associated facial lipoatrophy and the development of wrinkles due to facial fat loss or redistribution due to aging are 
different pathophysiological processes and may not be completely comparable in terms of severity, the cases discussed in the present article provide clinical confirmation of the benefits of three treatment sessions with injectable PLLA administered in at least three- to fourweek intervals or longer (eg, eight weeks). Both patients experienced clinical improvement in the nasolabial fold regions and in the alleviation of marionette lines. It is also noteworthy that the injection volume for each treatment session and for the overall treatment was different for each of the cases presented, thus underscoring the need to carefully consider each patient's age, severity of deficit and treatment goals before beginning treatment. Furthermore, such practice helps to avoid overcorrection of the treatment area. We hope that the examples presented in the present article will help clinicians achieve a greater understanding of how best to use injectable PLLA in soft tissue augmentation.

Since the patients described above were treated, a clinical trial in which subjects were treated with injectable PLLA or human collagen (CosmoPlast, Allergan-Inamed, USA) at three-week intervals has been completed (40). In this study, there were three weeks between treatments; a mean of 3.2 injection sessions were required by subjects in the injectable PLLA group. Within three weeks of the final treatment with injectable PLLA, there were significant $(\mathrm{P}<0.001)$ improvements in wrinkle assessment scores compared with baseline; the improvements continued to increase until the 13 -month assessment period, and were maintained at the 19- and 25-month assessment periods. The safety profiles of injectable PLLA and human collagen

\section{REFERENCES}

1. American Society of Plastic Surgeons. 2009 Report of the 2008 Statistics National Clearinghouse of Plastic Surgery Statistics. Arlington Heights: American Society of Plastic Surgeons, 2009.

2. Vleggaar D. Facial volumetric correction with injectable poly-L-lactic acid. Dermatol Surg 2005;31:1511-7.

3. Donofrio LM. Fat distribution: A morphologic study of the aging face. Dermatol Surg 2000;26:1107-12.

4. Garg A. Lipodystrophies. Am J Med 2000;108:143-52.

5. Ascher B, Coleman S, Alster T, et al. Full scope of effect of facial lipoatrophy: A framework of disease understanding. Dermatol Surg 2006;32:1058-69.

6. Sterling JB, Hanke CW. Poly-L-lactic acid as a facial filler. Skin Ther Lett 2005;10:9-11.

7. Eppley BL, Dadvand B. Injectable soft-tissue fillers: Clinical overview. Plast Reconstr Surg 2006;118:98e-106e.

8. Haneke E. Skin rejuvenation without a scalpel. I. Fillers. J Cosmet Dermatol 2006;5:157-67.

9. Juvéderm Ultra Plus. Santa Barbara: Allergan Inc, 2008.

10. Lupo MP, Smith SR, Thomas JA, Murphy DK, Beddingfield FC III. Effectiveness of Juvéderm Ultra Plus dermal filler in the treatment of severe nasolabial folds. Plast Reconstr Surg 2008;121:289-97.

11. Narins RS, Brandt F, Leyden J, Lorenc ZP, Rubin M, Smith S. A randomized, double-blind, multicenter comparison of the efficacy and tolerability of Restylane versus Zyplast for the correction of nasolabial folds. Dermatol Surg 2003;29:588-95.

12. Carruthers A, Carey W, De Lorenzi C, Remington K, Schachter D, Sapra S. Randomized, double-blind comparison of the efficacy of two hyaluronic acid derivatives, Restylane Perlane and Hylaform, in the treatment of nasolabial folds. Dermatol Surg 2005;31:1591-8.

13. Bosniak S, Cantisano-Zilkha M, Glavas IP. Nonanimal stabilized hyaluronic acid for lip augmentation and facial rhytid ablation. Arch Facial Plast Surg 2004;6:379-83.

14. Bauman L. CosmoDerm/CosmoPlast (human bioengineered collagen) for the aging face. Facial Plast Surg 2004;20:125-8.

15. Baumann L, Kaufman J, Saghari S. Collagen fillers. Dermatol Ther 2006;19:134-40.

16. Echavez M, Horstman W. Relationship between lipoatrophy and quality of life. AIDS Read 2005;15:369-75.

17. Radiesse injectable implant. Franksville: BioForm Medical Inc, 2006.

18. Sculptra Aesthetic. Bridgewater: Dermik Laboratories, a business of sanofi-aventis U.S. LLC, 2009.

19. Sculptra. Bridgewater: Dermik Laboratories, a business of sanofi-aventis U.S. LLC, 2006. were similar, with a higher incidence of adverse events in collagen recipients; the incidences of nodules and papules following injectable PLLA were $7 \%$ and $9 \%$, respectively. Additional studies may help to support the value of administering injectable PLLA in three sessions for the aesthetic correction of facial contour deficits, and to determine appropriate patient selection criteria for use of this approach.

\section{CONCLUSION}

In our experience with injectable PLLA in immunocompetent individuals, soft tissue augmentation over the course of a mean of three treatment sessions, at three- to four-week intervals, has produced optimal results. It is important to carefully evaluate the patient after each treatment session and to individualize follow-up injections and timing because each patient will respond differently to the use of injectable PLLA.

ACKNOWLEDGEMENTS: Editorial support for the present article was provided by the editorial staff at Embryon (New Jersey, USA). This article was funded by Dermik Laboratories, sanofi-aventis U.S. The authors thank Lynne Schneider, who assisted in the preparation of the article based on comments provided by the authors.

DISCLOSURE: The authors are fully responsible for all content, editorial decisions, and opinions expressed in the article, and neither received any financial compensation or honoraria related to the development of this manuscript.
20. Valantin M-A, Aubron-Olivier C, Ghosn J, et al. Polylactic acid implants (New-Fill) to correct facial lipoatrophy in HIV-infected patients: Results of the open-label study VEGA. AIDS 2003;17:2471-7.

21. Moyle GJ, Lysakova L, Brown S, et al. A randomized open-label study of immediate versus delayed polylactic acid injections for the cosmetic management of facial lipoatrophy in persons with HIV infection. HIV Med 2004;5:82-7.

22. Moyle GJ, Brown S, Lysakova L, Barton SE. Long-term safety and efficacy of poly-L-lactic acid in the treatment of HIV-related facial lipoatrophy. HIV Med 2006;7:181-5.

23. Bos RRM, Rozema FR, Boering G, et al. Degradation of and tissue reaction to biodegradable poly(L-lactide) for use as internal fixation of fractures: A study in rats. Biomaterials 1991;12:32-6.

24. Gogolewski S, Jovanovic M, Perren SM, Dillon JG, Hughes MK. Tissue response and in vivo degradation of selected polyhydroxyacids: polylactides (PLA), poly(3-hydroxybutyrate) (PHB), and poly(3-hydroxybutyrate-co-3-hydroxyvalerate) (PHB/VA). J Biomed Mater Res 1993;27:1135-48.

25. Lemperle G, Morhenn VB, Pestonjamasp V, Gallo RL. Migration studies and histology of injectable microspheres of different sizes in mice. Plast Reconstr Surg 2004;113:1380-90.

26. Böstman O, Viljanen J, Salminen S, Pihlajamäki H. Response of articular cartilage and subchondral bone to internal fixation devices made of poly-L-lactide: A histomorphometric and microradiographic study on rabbits. Biomaterials 2000;21:2553-60.

27. Hasegawa Y, Sakano S, Iwase T, Warashina H. The long-term behavior of poly-L-lactide screws in a minipig fracture model: Preliminary report. J Biomed Mater Res 2002;63:679-85.

28. Pihlajamäki $H$, Böstman $O$, Tynninen $O$, Laitinen $O$. Long-term tissue response to bioabsorbable poly-L-lactide and metallic screws: An experimental study. Bone 2006;39:932-7.

29. Rotunda AM, Narins RS. Poly-L-lactic acid: A new dimension in soft tissue augmentation. Dermatol Ther 2006;19:151-8.

30. El-Beyrouty C, Huang V, Darnold CJ, Clay PG. Poly-L-lactic acid for facial lipoatrophy in HIV. Ann Pharmacother 2006;40:1602-6.

31. Keni SP, Sidle DM. Sculptra (injectable poly-L-lactic acid). Facial Plast Surg Clin North Am 2007;15:91-7, vii.

32. Sherman RN. Sculptra: The new three-dimensional filler. Clin Plast Surg 2006;33:539-50.

33. Lowe NJ. Optimizing poly-L-lactic acid use. J Cosmet Laser Ther 2008;10:43-6. 
34. Beer KR, Rendon MI. Use of Sculptra in esthetic rejuvenation. Semin Cutan Med Surg 2006;25:127-31.

35. Leonard AL, Hanke CW. A protocol for facial volume restoration with poly-L-lactic acid. J Drugs Dermatol 2006;5:872-7.

36. Broder KW, Cohen SR. An overview of permanent and semipermanent fillers. Plast Reconstr Surg 2006;118:7S-14S.

37. Narins RS, Bowman PH. Injectable skin fillers. Clin Plast Surg 2005;32:151-62.

38. Barton SE, Engelhard P, Conant M. Poly-L-lactic acid for treating HIV-associated facial lipoatrophy: A review of the clinical studies. Int J STD AIDS 2006;17:429-35.

39. Mest DR, Humble G. Safety and efficacy of poly-L-lactic acid injections in persons with HIV-associated lipoatrophy: The US experience. Dermatol Surg 2006;32:1336-45.

40. Narins RS, Baumann L, Brandt FS, et al. A randomized study of the efficacy and safety of injectable poly-L-lactic acid versus humanbased collagen implant in the treatment of nasolabial fold wrinkles. J Am Acad Dermatol 2010;62:448-62.

41. American Society of Plastic Surgeons. Perception of the Injection: American Women's Perception of Cosmetic Facial Injectables. A Harris Interactive Survey. <www.plasticsurgery.org/Documents/ Media/Perception-of-the-Injection-American-Women-s-Perceptionof-Cosmetic-Facial-Injectables.pdf> (Accessed on May 4, 2010).

42. Narins RS. Minimizing adverse events associated with poly-L-lactic acid injection. Dermatol Surg 2008;34(Suppl 1):S100-S104.

43. Lowe NJ, Maxwell CA, Lowe P, Shah A, Patnaik R. Injectable poly-L-lactic acid: 3 years of aesthetic experience. Dermatol Surg 2009;35(Suppl 1):344-9.

44. Fitzgerald R, Vleggaar D, Burgess C. Facial dermal fillers. Aesthet Surg J 2008;28:699-701.
45. Butterwick K, Lowe NJ. Injectable poly-L-lactic acid for cosmetic enhancement: Learning from the European experience. J Am Acad Dermatol 2009;61:281-93.

46. Vleggaar D, Fitzgerald R. Dermatological implications of skeletal aging: A focus on supraperiosteal volumization for perioral rejuvenation. J Drugs Dermatol 2008;7:209-20.

47. Day DJ, Littler CM, Swift RW, Gottlieb S. The Wrinkle Severity Rating Scale: A validation study. Am J Clin Dermatol 2004;5:49-52.

48. Vander Straten M, Carrasco D, Paterson MS, McCrary ML, Meyer DJ, Tyring SK. Tobacco use and skin disease. South Med J 2001;94:621-34.

49. Freiman A, Bird G, Metelitsa AI, Barankin B, Lauzon GJ. Cutaneous effects of smoking. J Cutan Med Surg 2004;8:415-23.

50. Friedman $\mathrm{O}$. Changes associated with the aging face. Facial Plast Surg Clin North Am 2005;13:371-80.

51. Donath AS, Glasgold RA, Glasgold MJ. Volume loss versus gravity: New concepts in facial aging. Curr Opin Otolaryngol Head Neck Surg 2007;15:238-43.

52. Zins JE, Moreira-Gonzalez A. Cosmetic procedures for the aging face. Clin Geriatr Med 2006;22:709-28.

53. Lam SM, Azizzadeh B, Graivier M. Injectable poly-L-lactic acid (Sculptra): Technical considerations in soft-tissue contouring. Plast Reconstr Surg 2006;118:55S-63S.

54. Vleggaar D, Bauer U. Facial enhancement and the European experience with Sculptra (poly-L-lactic acid). J Drugs Dermatol 2004;3:542-7.

55. Burgess CM. Principles of soft tissue augmentation for the aging face. Clin Interv Aging 2006;1:349-55.

56. Cohen SR, Born TM. Facial Rejuvenation with Fillers. In: Codner MA, ed. London: Saunders Elsevier, 2009. 